\title{
A Era da Vitalidade: \\ uma cartografia do presente
}

ROSE, Nikolas.

A política da própria vida: biomedicina, poder e subjetividade no século XXI.

São Paulo: Paulus, 2013.

I ${ }^{1}$ Angela Vasconi Speroni I

${ }^{1}$ Instituto de Estudos em Saúde Coletiva, Universidade Federal do Rio de Janeiro. Rio de Janeiro-RJ, Brasil (angelasperoni@gmail.com).

DOI: http://dx.doi.org/10.1590/S0103-733120160001019

No acender das luzes do século XXI, o sociólogo britânico Nikolas Rose ${ }^{1}$ apresenta um convite à reflexão acerca das controvérsias instauradas com a chegada da Era das Possibilidades médicas, com o advento de novas tecnologias, ao mesmo tempo fantásticas e perturbadoras. A partir de uma cartografia do presente, Rose desenvolve uma análise minuciosa de processos históricos e culturais que compõem e alicerçam o cenário de desenvolvimento de biotecnologias, revelando continuidades e mudanças que constituem modalidades inovadoras de gestão da vida, dos indivíduos e de seus corpos. O livro A política da própria vida: biomedicina, poder e subjetividade no século $X X T^{2}$ vai além de uma coletânea de ensaios previamente publicados pelo autor e seus interlocutores, decorrentes de simpósios e seminários realizados desde o final da década de 1990. Nas palavras de Rose, a obra é constituída por conceitos "destilados", frutos do diálogo com pesquisadores da área das biociências e das ciências da vida, como Carlos Novas, Paul Rabinow e Sarah Franklin.

A partir de amplo levantamento de exemplos de avanços nos campos da genética, das tecnologias reprodutivas, da terapia celular, da psicofarmacologia, entre outros saberes e técnicas que compõem um novo mercado de consumo em saúde, Rose revela a instauração de uma nova "ética somática". Tal conceito vincula-se à perspectiva de que o gerenciamento dos riscos da doença e do 
envelhecimento, o melhoramento contínuo do corpo, da longevidade e vitalidade ampliam as possibilidades de gestão do indivíduo sobre si, modelando ativamente o curso da própria vida, mediante atos de escolha imbuídos de esperança.

Rose introduz o texto com a relativização de seu ponto de vista. Em primeiro lugar, afirma partir de um presente situado, enquanto habitante do seleto grupo das "democracias liberais avançadas do primeiro mundo". ${ }^{3}$ Ao mesmo tempo, o autor se coloca em um espaço intermediário, sem sair em defesa de especulaçōes sobre o futuro nem assumir uma visão pessimista puramente crítica. O foco de seu trabalho incide sobre o mapeamento de mutações significativas que contribuíram para a instituição de uma "forma de vida emergente", ${ }^{4}$ e culminaram na modelação de uma nova prática política nomeada de "política vital" ou "política da vida em si mesmo".

Influenciado pelos estudos de Foucault, Rose avança em direção à investigação das distintas modalidades da biopolítica na contemporaneidade. Após a passagem de um poder soberano para um poder disciplinar, centrado na regulação dos indivíduos e do corpo social (FOUCAULT, 1988), surgem novas estratégias de gestão da vida, frutos de uma reorganização dos poderes do Estado, com ênfase crescente na responsabilidade individual. A ampliação da capacidade dos indivíduos controlarem, projetarem, modelarem e remodelarem seus corpos e suas vidas conduz à abertura de possíveis futuros, organizados em torno de uma tensão entre expectativas e medos, esperança e temores, possibilidades e controvérsias.

Rose estrutura o livro em torno de cinco conceitos-chave, que consistem em vias de acesso às transformaçôes da biomedicina e da biopolítica no século XXI: molecularização, otimização, subjetificação, expertise e bioeconomia.

No primeiro capítulo, o autor resgata a história foucaultiana da medicina (FOUCAULT, 1977) até chegar à biopolítica molecular contemporânea. Rose demonstra de que maneira a fragmentação do corpo em tecidos transferíveis, células, fragmentos de DNA, entidades moleculares que podem ser identificadas, isoladas, manipuladas e comercializadas, culminou em práticas inovadoras de intervenção, que permitem uma mobilidade dos elementos da vida, possibilitando sua entrada em novos círculos de vitalidade.

Rose aponta a formação de um novo estilo de pensamento ${ }^{5}$ da biomedicina na contemporaneidade, que não se restringe à forma de explanação. Antes, trata-se do que há para (ou deve) ser explicado. O cérebro, para as neurociências 
contemporâneas, por exemplo, não é o que era nos anos 1950; a biologia celular não é a mesma dos anos 1960; o "gene" não é o que era antes dos genomas serem sequenciados. $\mathrm{O}$ novo estilo de pensamento que assumiu forma nas ciências da vida modificou de tal sorte seus objetos, que eles aparecem com novas propriedades e relações com outros objetos. O "vital" nos seres humanos referese, portanto, ao modo como o conhecimento molecular tem sido vinculado a uma gama de técnicas de experimentação, que passaram a intervir na vida, exatamente no nível molecular.

As chamadas "tecnologias de otimização" possibilitam modalidades inovadoras de atuação sobre a vitalidade, atribuindo lugar central à experiência física e corporal. O laboratório passou a ser um tipo de fábrica para formas de vida emergentes. Para além de concepções de saúde e doença, a criação de novos "indivíduos somáticos” está orientada para o futuro, o aprimoramento contínuo, a automaximização da vida. Verifica-se uma mudança epistemológica, fundada na possibilidade de remodelar o que deve ser um organismo biológico, calcular e manipular seus processos vitais, para maximizar seu funcionamento e incrementar seus resultados. O foco incide sobre um futuro vital pela ação no presente, mediante novas "tecnologias da vida".

A emergência de novas concepções sobre os seres humanos, o que devem fazer e o que podem esperar, recodifica deveres, direitos e expectativas, não somente em relação a seus corpos, mas especialmente em relação às próprias vidas. $\mathrm{O}$ surgimento de uma "cidadania biológica" implica desenvolver distintas formas de subjetificação e sociabilidade, modalidades alternativas de governar a vida, transformando os caminhos pelos quais os indivíduos se relacionam, tanto internamente quanto com os outros.

Se, até meados do século XX, a saúde havia se tornado um valor ético central nas sociedades industriais do Ocidente, a chegada do "século técnico" acarretou a instauração do imperativo da vitalidade, um novo regime de responsabilidade dirigido à maximização das potencialidades do corpo. Em seu nível mais ínfimo, molecular, a vida passa a ser aberta à política, culminando no surgimento do que Rose nomeia de uma nova "ética somática".

O que está em jogo, portanto, são possibilidades inovadoras de gestão da vida, por intermédio de um regime do cuidado de si, vinculado à ideia de constituição de si como experiência, como sujeito moral ativo, capaz de aperfeiçoamento 
contínuo. Novas moralidades são instituídas, refletindo e reiterando o imperativo da escolha, da obrigação moral de ações voltadas à garantia de um "futuro melhor”, uma vida saudável, extensa, prazerosa e feliz.

A instauração desses novos regimes éticos sustenta-se em uma expertise, que deve ser compartilhada "por todos". Surgem subprofissões que exigem uma "expertise somática”, assim como um diálogo permanente com agentes de negociação e legitimação do conhecimento. Neste contexto, é possível encontrar formas de autoridade, que vão além dos "peritos somáticos" tradicionalmente envolvidos - profissionais da biomedicina, enfermeiras, biólogos, entre outros agentes cujas intervenções na vida das pessoas ampliam-se largamente. Entram em cena múltiplos atores, desde terapeutas ocupacionais, fisioterapeutas, nutricionistas, peritos em promoção da saúde, até geneticistas que trabalham em parceria com grupos de pacientes e de famílias, especialistas em medicina reprodutiva e terapeutas de células-tronco, cujas pesquisas consistem em foco de peregrinações, na esperança de cura para muitas doenças. Formam-se, assim, laços inovadores entre verdade e capitalização. A vitalidade é decomposta em uma série de objetos imbuídos de valor, tornando a vida maleável a novas relaçôes econômicas. Os novos "peritos da vida em si mesma” estão enredados em um novo campo econômico - a bioeconomia - e uma nova forma de capital - o biocapital.

Rose desenvolve seu texto ancorado nestes cinco conceitos, partindo do mapeamento de transformações na lógica da biomedicina, e suas relaçôes com consumidores, instituições privadas e entidades regulatórias, para refletir sobre o advento de inovaçôes biotecnológicas, e suas repercussões, nos níveis molecular, público e privado. $\mathrm{O}$ segundo capítulo é dedicado à revisão dos conceitos de vida e política, a partir do diálogo com as obras de Canguilhem (1943), Foucault (1988), Bauman (1998), Agamben (2002), entre outros autores. Rose explicita de que forma a descoberta "do gene" conduziu à alteração das definiçốes de vida, herança e desenvolvimento, assim como ao surgimento de entidades liminares, decorrentes das novas tecnologias de reprodução e com células-tronco. Esperma, óvulos não fertilizados e fertilizados, embriōes em diferentes estágios de desenvolvimento e linhagens de células-tronco transformaram as fronteiras da vitalidade, acarretando amplo debate biomédico, bioético e político, acerca de seus direitos e proteção, com deliberações distintas em cada país. 
Frente à proliferação de mecanismos de atuação, modelação e regulação da vida, dos indivíduos e seus corpos, Rose ressalta a utilidade analítica da perspectiva da biopolítica de Foucault, para pensar de que forma o caráter vitalista conferido à existência conduziu à produção de sujeitos políticos. Nesse sentido, o autor questiona certas perspectivas críticas, que protestam contra o caráter eugênico do determinismo genético, deslocando o foco para a formação de novas subjetividades. Para ele, a relação contemporânea entre a vida biológica do indivíduo e o bem-estar da coletividade, do ponto de vista das racionalidades políticas "liberais avançadas", não se restringe à busca por classificar, identificar e eliminar pessoas com constituição defeituosa ou promover a reprodução dos que possuem características desejáveis, em nome da boa saúde da população, da nação ou da raça. Antes, tal relação se refere a uma variedade de estratégias que buscam identificar, tratar, gerir ou administrar aquelas pessoas, grupos ou ambientes, nos quais o risco é considerado alto.

Na Era da Vitalidade, o mapeamento do risco denota novas formas de pensar e agir, que envolvem cálculos acerca de possíveis futuro; "cada ato de opção aberto pela nova biomedicina deveras pressupõe um julgamento de valor em um campo de probabilidades modelado por esperanças" (p. 81). As novas ciências da vida, das quais a genômica é apenas um aspecto, abrem um espaço de incerteza, e não de certezas. Nesse cenário de possibilidades, em que a biologia é uma oportunidade - e não um destino -, exigências de medidas individuais e coletivas de gerenciamento de risco proliferam e se globalizam, dando origem a uma "forma de vida emergente".

No terceiro capítulo, Rose desenvolve a noção de uma forma de vida emergente nas democracias liberais avançadas, definindo-a a partir de duas dimensõeschave: a suscetibilidade e o aprimoramento. Para o autor, embora a medicina de saúde pública tenha se engajado há tempos em estratégias de prevenção da doença e promoção da saúde, a instauração da era da genômica, com o desenvolvimento do Projeto Genoma Humano e a proliferação da farmacologia, fez com que a intervenção prévia ou de longo prazo se tornasse central, na política da vida do século XXI. A suscetibilidade está vinculada ao planejamento da ação, ao passo que a ciência contemporânea se orienta segundo imagens do futuro, que postulam esperanças, subvençóes para pesquisas e estratégias de investimento, sob um regime da obrigatoriedade de ação no presente. Rose aponta os perigos 
da manipulação dessa imaginação científica, em face do exagero comercial e publicitário em torno dos progressos, promessas e narrativas fictícias de futuros potenciais. Por outro lado, é cuidadoso ao apresentar pontos de vista como de Fukuyama (2003), Habermas (2004) e Kass (2003), que insistem na ameaça do uso indiscriminado da biotecnologia, na produção e promoção de metas e desejos seculares dos seres humanos, como os ideais de corpos eternamente jovens, filhos perfeitos e almas felizes.

$\mathrm{Na}$ perspectiva analítica de Rose, a proliferação de intervenções biomédicas sobre os indivíduos, segundo a ótima da suscetibilidade e do aprimoramento, revela o imperativo da ação com vistas à otimização da vitalidade futura. Mais do que uma lógica de correção, o aprimoramento relaciona-se com

[...] tentativas de otimizar ou de incrementar quase qualquer capacidade do corpo ou da alma humanos - força, resistência, longevidade, atenção, inteligência - para abri-la ao artifício e incluir seu gerenciamento dentro da remessa da biomedicina para a clínica e para o mercado (p. 123).

Nesse contexto, a indústria psicofarmacêutica cresce, ancorada em uma nova ética da autenticidade, na qual as propagandas são dirigidas às pessoas, vinculadas à necessidade de cada um se tornar o ator no centro da própria vida. O "novo regime do si-mesmo" não promete um novo si-mesmo, com "pílulas" do bem-estar e da felicidade, mas um retorno ao verdadeiro si-mesmo, com o poder de refazer-se, para atingir sua realização máxima.

As múltiplas transações entre expertise e subjetividade, e as diversas injunções e desejos realizados de reformar e refazer nós mesmos através de intervenção calculada em nome da nossa autenticidade, autorrealização e liberdade, têm sido centrais para o "gerenciamento do si-mesmo" em democracias liberais avançadas. O que é novo, talvez, é a centralidade concebida ao soma, à carne, aos órgãos, aos tecidos, às células, às sequências dos genes e à corporeidade molecular para nossas maneiras individuais e coletivas de compreender e de gerenciar nós mesmos como seres humanos (p. 153-4).

No capítulo seguinte, Rose segue na perspectiva da primazia do risco, enquanto estruturante para criação de novos sujeitos, mediante a instauração de uma “individualidade somática”. A formação de novas subjetividades está vinculada às dimensões de livre arbítrio, intencionalidade e responsabilidade. Nessa forma de vida emergente, o indivíduo se vê obrigado a engajar-se em um autogerenciamento responsável, calculando riscos e benefícios, debatendo e justificando suas escolhas. Trata-se de agir no presente, na direção de prováveis futuros. Há, portanto, um deslizamento: da perspectiva molecular, desde a molecularização dos processos da 
vida, aos níveis da biologia, genética e biomedicina, até uma dimensão política, centrada na produção de novas subjetividades e moralidades.

No quinto capítulo, Rose desenvolve a ideia de que a produção de novas subjetividades conduz à implementação de uma "cidadania biológica". ${ }^{6}$ Esse modelo contemporâneo de cidadania reflete a importância crescente da corporeidade para a constituição da identidade, na medida em que as pessoas passam a se reconhecer a partir do conhecimento da própria individualidade somática. Por outro lado, o regime da responsabilidade por si acaba por modelar a formação de novos coletivos. Formas inovadoras de coletivização, nomeadas por Rabinow (2002) de "biossocialidades", promovem a constituição de uma identidade partilhada, segundo uma concepção biológica.

A cidadania biológica é tanto individualizadora quanto coletivizadora. No entanto, "quer em seus momentos de individualização, quer de coletivização, a cidadania biológica contemporânea age dentro do campo da esperança" (p. 193). A esperança desempenha papel primordial, ao orientar projetos compartilhados, em um movimento em prol do controle do futuro, além de uma crença ambivalente no progresso. A instrumentalização e manipulação da esperança promove a formação de alianças entre diferentes tipos de agentes - pacientes, cientistas, organizações médicas, indústria farmacêutica, instâncias regulatórias e agências de financiamento -, com dimensões locais, nacionais e transnacionais. A vitalidade de cada um e de "todos nós" torna-se uma fonte potencial de valor, o "biovalor". Nos novos circuitos contemporâneos de biovalor e na nova economia de mercado da saúde que promovem, a cidadania biológica é, ao mesmo tempo, financeira, ética, pública e ativa. As distintas possibilidades de geração de riqueza não estão vinculadas apenas ao compartilhamento do conhecimento biológico e biomédico, mas a novos valores éticos.

Aqui [dentro de um regime ético do si-mesmo], cada pessoa está compreendida como indivíduo prudente, mas empreendedor, modelando ativamente o curso da sua vida através de atos de escolha, atividades que se estendem para a busca da saúde perante o medo da doença e o gerenciamento dos riscos - agora as suscetibilidades genéticas - da doença. [...] daí o cidadão biológico responsável ativo deve se engajar num trabalho constante de autoavaliação e de modulação da conduta, da dieta, do estilo de vida, do regime medicamentoso, em resposta às exigências instáveis do corpo suscetível” (p. 219).

Surgem novas relações entre verdade, poder e comércio. Na interface entre esperança e responsabilidade, instaura-se o que Rose e Novas (2005) nomeiam 
como uma "economia política da esperança". Grupos de pacientes se articulam em torno de estratégias inovadoras de ativismo político, pela reivindicação de direitos, pelo acesso a recursos específicos, como ensaios clínicos e testes experimentais e, de modo mais amplo, pela ação direta sobre a produção de verdades, do conhecimento científico e tecnologias geradas pela pesquisa.

Nos capítulos seguintes, Rose segue o desenvolvimento de sua cartografia do presente, mapeando exemplos das transformações ocorridas na passagem do século XX para o XXI, que culminaram na produção da "política da vida em si mesma". No capítulo seis, o autor retoma o debate acerca de projetos de identificação da relação entre raça e suscetibilidades genéticas para doença, bem como a produção e comercialização de produtos farmacêuticos "baseados na raça".

No capítulo sete, Rose revela os processos de molecularização do diagnóstico psiquiátrico, que favoreceram a fabricação de moléculas terapêuticas precisas, para atacar anomalias neuroquímicas pré-sintomáticas, detectadas pelo rastreamento de suscetibilidades cerebrais. Ao se referir à "cidadania neuroquímica", aponta diferenças em relação aos padrões de ativismo biológico em torno da compreensão genética e somática dos indivíduos. $\mathrm{O}$ autor afirma que as transformações no pensamento, nas práticas da psiquiatria e da psicofarmacologia contribuem para que os próprios indivíduos e suas autoridades - clínicos gerais, enfermeiros, professores e pais - se tornem capazes de recodificar as variações nos humores, nas emoções, nos desejos e pensamentos, e a interferir neles, à luz dessas crenças. Cada indivíduo neuroquímico tem, portanto, a obrigação de assumir o controle dessas modulações, em nome da maximização do próprio potencial, atenuando as fronteiras entre diagnóstico, tratamento e recuperação.

No capítulo oito, Rose apresenta a nova "Biologia do Controle", decorrente da ideia de que a criminalidade pode estar escrita no corpo, segundo uma constituição física e moral degenerada, herdada, inalterável. Essa perspectiva coloca a possibilidade de controle, por meio de estratégias de segurança pública, sob a justificativa de proteção de "pessoas normais", contra ameaças oriundas de possíveis agressores. Nesse sentido, a ênfase recai sobre a identificação de processos biológicos, marcadores genéticos e fatores de risco para conduta agressiva e antissocial, com vistas ao desenvolvimento de técnicas para identificar e "tratar" quem ofereça riscos - via terapia genética, psicofarmacologia, controle ambiental, reestruturação cognitiva, entre outras técnicas. Nessa micropolítica de práticas 
contemporâneas de controle do crime, estão envolvidos novos jogos biológicos de verdade e identidade, articulados a novas concepções biológicas da origem de condutas patológicas. Na biocriminologia, explanações biológicas de tendência a comportamento antissocial estão articuladas a noções de responsabilidade moral e culpabilidade individual que não são mitigadas pela prova de causação biológica. A dimensão central refere-se às dimensões da autonomia da escolha e da responsabilidade pessoal, invocando a jurisprudência da saúde pública e da proteção social. Assim como no mesmo estilo de pensamento do restante da biologia e da neurociência molecular contemporâneas, a lógica prevalente não é do determinismo biológico, mas da suscetibilidade, da predição e prevenção. Os crimes são, portanto, concebidos em termos morais, como patologias de indivíduos que "rejeitam os laços de uma comunidade moral e que violam as normas da liberdade e do autocontrole que jazem no coração da ordem moral de uma sociedade liberal avançada” (p. 348).

Rose encerra sua obra com a afirmação da "Ética somática e o espírito do biocapital", em um paralelo com a tese weberiana que apresentou as bases da formação do capitalismo (WEBER, 2004). A instauração da Era da Vitalidade propiciou uma quebra das fronteiras entre vida e morte, natural e artificial, possibilitando uma alteração destes conceitos, em processos de negociação. A biologia não é mais o destino, os julgamentos não são mais organizados segundo uma equação de normalidade e patologia, saúde e doença. No mundo do risco, da suscetibilidade, da prudência e da previsão, a vida é concebida e manipulada em seus níveis moleculares mais ínfimos. A corporalidade transformou-se em um dos lugares mais relevantes para julgamentos éticos.

A vocação políticas das ciências da vida está ligada à crença de que na maioria dos casos, talvez em todos eles, se não agora, então no futuro, as pessoas oferecem risco, danificadas, defeituosas ou afligidas, uma vez identificadas e avaliadas, podem ser tratadas ou transformadas mediante intervenção no nível molecular (p. 352).

Os seres humanos tornaram-se mais biológicos, ao passo em que a vitalidade do corpo está cada vez mais aberta à mecanização. A noção de uma nova ética somática, como modo de compreender, modelar e gerenciar a conduta cotidiana das próprias vidas está inextricavelmente vinculada à bioeconomia, mediante uma virtude moral particular, acrescida pela busca de lucro. A biopolítica do século XXI está, portanto, intrinsecamente articulada à capitalização da vida e ao "espírito do biocapital". 


\section{Referências}

AGAMBEN, G. Homo sacer: o poder soberano e a vida nua. Belo Horizonte: UFMG, 2002. 207p.

BAUMAN, Z. Modernidade e holocausto. Rio de Janeiro: Jorge Zahar, 1998. 266p.

CANGUILHEM, G. O normal e o patológico. Rio de Janeiro: Forense Universitária, 1978 [1943]. 307p.

FLECK, L. Gênese e desenvolvimento de um fato científico. Belo Horizonte: Fabrefactum, 2010. 201p.

FOUCAULT, M. A história da sexualidade I: a vontade de saber. Rio de Janeiro: Graal, 1988. 176p.

O nascimento da clínica. Rio de Janeiro: Forense Universitária, 1977. 231p.

FUKUYAMA, F. Nosso futuro pós-humano: consequências da revolução da biotecnologia. Rio de Janeiro: Rocco, 2003. 268p.

HABERMANS, J. O futuro da natureza humana: a caminho da eugenia liberal? São Paulo: Martins Fontes, 2004. 160p.

KASS, L. Beyond therapy: biotechnology and the pursuit of happiness. Nova Iorque, Dana Press, 2003. 373p.

RABINOW, P. Artificialidade e iluminismo: da sociobiologia à biossociabilidade. In: . Antropologia da razão: ensaios de Paul Rabinow. Rio de Janeiro: Relume-Dumará, 2002. p. 135-157.

ROSE, N. A política da própria vida: biomedicina, poder e subjetividade no século XXI. São Paulo: Paulus, 2013. 396p.

ROSE, N.; NOVAS, C. Biological Citizenship. In: ONG, A.; COLLIER, S. (Org.). Global Assemblages: technology, politics, and ethics as anthropological problems. Malden, M.A.: Blackwell, 2005. p. 439-63.

WEBER, M. A ética protestante e o espirito do capitalismo. São Paulo: Companhia das Letras, 2004. 335p.

\section{Notas}

${ }^{1}$ Nikolas Rose é professor do Departamento de Sociologia e Coordenador do Centro de Pesquisa para o Estudo de Biociências, Biomedicina, Biotecnologia e Sociedade (BIOS) da London School of Economics and Political Science.

${ }^{2} \mathrm{O}$ livro A politica da própria vida: biomedicina, poder e subjetividade no século XXI foi publicado originalmente pela Princeton University Press em 2007 e lançado no Brasil pela editora Paulus em 2013. A tradução é de Paulo Ferreira Valerio. 
${ }^{3} \mathrm{O}$ autor não define quais são os países que compõem esse grupo. No entanto, em certo trecho, refere-se aos Estados Unidos como o local "onde se pode esperar que tais desenvolvimentos sejam os mais avançados” (p. 325).

${ }^{4}$ Rose apropriou-se da ideia de "forma de vida emergente" apresentada por Stefan Beck e Michi Knecht, durante simpósio realizado na Alemanha, em 2003. No terceiro capítulo desse livro, o autor desenvolve sua perspectiva sobre o conceito: "Algo novo que está surgindo do entretecimento de formas de pensar e de agir em uma série de práticas - médicas, legais, econômicas, politicas, éticas -, mesmo não sendo postuladas por nenhuma delas" (p. 121).

5 Para Fleck (2010), o "estilo de pensamento" de determinada área do saber corresponde a construções compartilhadas acerca de uma certa forma de pensar e perceber os fenômenos que constituem seu objeto de estudo. O autor denomina de "coletivo de pensamento" o grupo de pesquisadores que se organiza em torno de determinado estilo. Cada pesquisador participa também de outros coletivos, promovendo fluxos de ideias e conceitos, que acabam por gerar transformaçôes mútuas nesses estilos, seus saberes, normas e práticas.

${ }^{6}$ Esse capítulo foi originalmente publicado em parceria com Carlos Novas, em 2005, sob o título "Cidadania Biológica". 